\title{
Determination of equivalent and optimal sizes of wedge tip from flange for the static perforation of soil
}

\author{
Olexander Posmituha, ${ }^{1, *}$, Svyatoslav Kravets ${ }^{2}$, Volodymyr Suponyev ${ }^{3}$, and Kazimir \\ Glavatsky ${ }^{1}$ \\ ${ }^{1}$ Dnipropetrovsk National University of Railway Transport named after Academician V. Lazaryan, \\ Dnipro, Ukraine \\ ${ }^{2}$ National University of Water and Environmental Engineering, Rivne, Ukraine \\ ${ }^{3}$ Kharkiv National Automobile and Highway University, Kharkiv, Ukraine
}

\begin{abstract}
The purpose of the study is to create a new design of the working tip for the perforation of the soil when laying two or more buildings trenchless way and determine its rational parameters. Method. It is known that for static perforation in the formation of cavities in the soil for communication is traditionally used cone-shaped working elements, which is the most common, cheap and reliable. However, the study revealed inefficiency. The design of the working elements of the soil perforation for trenchless laying of two or more buildings simultaneously in the form of a tip, which consists of a wedge-shaped part and a control part in the form of a rectangle with half-cylinders. The basic principles and mathematical dependences of determining the size of the working body are described. Scientific novelty. Regularities of changes in soil pressure on the lateral, conical and wedge surface, flat and cylindrical part of the tip, allowed to obtain an analytical dependence for the calculation of the resistance force depending on the physical and mechanical properties of the soil, the diameter and the number of cases established simultaneously. Also, when comparing the cone-cylindrical and flat tips, it can be argued that the breakdown force of the flat tip decreases from 1.2 to 1.7 times.
\end{abstract}

\section{Analysis of literary data and problem statement}

General conformities to law of processes of perforation of soil and formation horizontallydirected mining holes expounded in works $[1,3,4,6,9,10]$, researches of influence of structural parameters working elements on the process of perforation in works $[2,3,6,9]$. Changes of descriptions of soil are in surrounding space of mining hole (well space) with static puncture of soil and the influence on the formation of a wellhead leader $[2,5,6]$. Researches on determination of rational and optimal sizes tip for to puncture the soil of working element of cone form for the decision of this task in works $[4,6]$.

For the first time such a form of cross section of the hole is considered that analytical dependence of resistance of moving of working organ is create from the form of working

* Corresponding author: AleksandrP@,3g.ua 
organ (Fig. 1.) and the number of linearly lengthy objects, what laid simultaneously. The got dependences give an opportunity to assert, that with this shape of the hole depending on the number of communications, which are laid simultaneously it is possible to decrease effort to 1.7 parts, and also to decrease the zone of structural changes in soil round the got cavity in comparing to the traditional cone tip. From work [6] it is known that the puncture of the soil by a cone tip it can be effective within the limits of diameter of mining hole, what is got from the condition of optimal resistance. It was so set, that the maximum reduction in the resistance to piercing takes place: for hard sandy loam at diameters $D=0.2 \ldots 0.25 \mathrm{~m}$, for semi-solid loam with diameters $D=0.13 \ldots 0.17 \mathrm{~m}$, for taut plastic clay at diameters $D=0.12 \ldots 0.13 \mathrm{~m}$. Obvious is that through such cavities the number of pipe laying is limited, especially paying attention to that, that their diameters fold not less than $100 \mathrm{~mm}$.

\section{Methodology of calculation of resistance of wedge tip}

We propose the construction of a groundbreaking working element (Fig. 1) for a simultaneous gasket two and more cases 3 , what is folded pricking wedge-shaped part 1 with the halves of cone and the calibration part 2 in form a rectangular cavity with half the cylinder at the edges.

Will define the law of change of closeness of soil on a thickness $d$ tip based on the equality of masses [6], what according to the chart of action of normal pressure of soil on a working elements (Fig. 1) looks like:

$$
(n-1) d^{2} \rho_{\text {nat }}=(n-1) d(d-2 x) \rho,
$$

where $d$ - the diameter of the linear-extending object (LEO); $n$ - quantity of LEO, which are simultaneously laid; $\rho_{x}-$ a law of change of closeness of soil is on the lateral verges of wedge on the height of cone surface; $\rho_{\text {nat }}-$ a closeness of soil is in the natural state; $x$ - deformation of soil by the frontal surface of tip.

Then law of change of normal pressure of soil on the frontal surface of tip in accordance with methodology [4] written down in a kind:

$$
q_{x}=E_{\text {soil }} \frac{2 x}{d}
$$

where $E_{\text {soil }}=\frac{1+\omega}{c_{k}} \frac{\rho_{\text {hard }}}{\rho_{\text {nat }}}-$ compression module of deformation of soil; $c_{k}-$ coefficient of compression of the soil [8], $\mathrm{MPa}^{-1}\left(c_{k}=0.07 \ldots 0.09\left(\omega_{T}-10\right)\right) ; \rho_{\text {hard }}$ - density of solid phase of soil (without pores); $\omega$ - humidity of soil, $\% ; \omega_{T}$ - limit of fluidity of soil.

The force of immersion of the tip consists of the effort of immersion of the wedge in height $h_{\text {wedge }}=(n-1) d$ that effort of immersion of two extreme halves of cones equivalent to effort of immersion of one cone diameter $d$.

$$
P_{\text {comeback. }}^{\triangleright}=P_{\text {wedge }}+P_{\text {cone. }} .
$$

Will define resistance of wedge:

$$
d P_{\text {wedge }}=2 q_{x} \partial F \sin \beta(1+f \cdot \operatorname{ctg} \beta) .
$$


where $\partial F$ - elementary area of frontal surface of wedge $\left(\partial F=\partial h \cdot \frac{\partial x}{\sin \beta}\right) ; 2 \beta-$ corner of intensifying of wedge; $f$ - a coefficient of friction of soil is on a wedge.
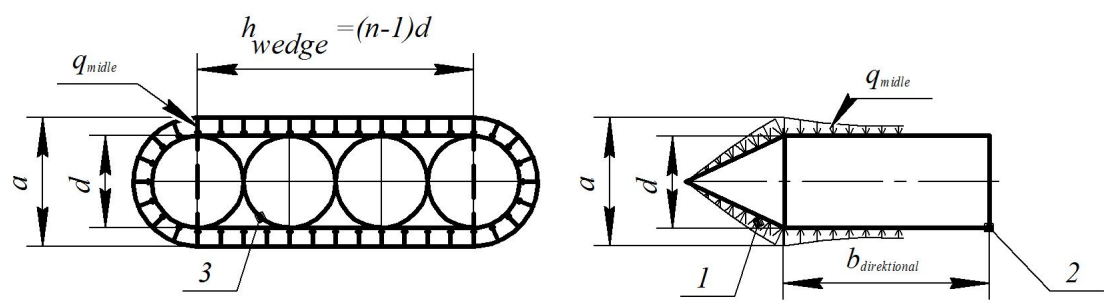

Fig. 1. Cross section of working elements: 1 - wedge piercing part with half cone sideways; 2 - calibrating part; 3 - cases that is laid.

Then

$$
\begin{gathered}
\partial P_{\text {wedge }}=E_{\text {soil }} \frac{4 x}{d} \partial h \frac{\partial x}{\sin \beta} \sin \beta(1+f \operatorname{ctg} \beta), \\
P_{\text {wedge }}=E_{\text {soil }} \frac{4 h_{\text {wedge }}}{d}(1+f \cdot \operatorname{ctg} \beta) \int_{0}^{d / 2} x \partial x=\frac{d \cdot h_{\text {wedge }}}{2} E_{\text {soil }}(1+f \cdot \operatorname{ctg} \beta) \\
P_{\text {wedge }}=\frac{(n-1) d^{2}}{2} E_{\text {soil }}(1+f c t g \beta) .
\end{gathered}
$$

Obviously, that total resistance the puncture consists of the resistance of the conical and wedge parts of the tip (Fig. 1) for a gasket $n$-casing. According to previous work $[4,6]$ authors, the theoretically determined resistance to penetration of the conical tip into the soil equals:

$$
P_{\text {comeback.cone. }}=\frac{\pi}{8} D^{2} E_{\text {soil }}(1+f \operatorname{ctg} \beta) \text {. }
$$

where $D$ - the size of the hole in which fit $n$-casing, what laid simultaneously (Fig. 2).

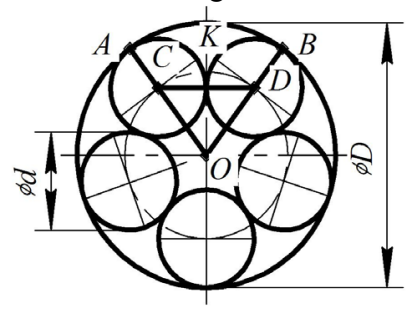

Fig. 2. Determination of opening diameter is at a group gasket $n$ - casing.

Consider the triangles $\triangle A O B, \triangle C O D$ та $\triangle K O D$.

Angle $\angle K O D=\frac{\pi}{n}$, from where

$$
\sin \frac{\pi}{n}=\frac{K D}{O D}, O D=\frac{K D}{\sin (\pi / n)}=\frac{d}{2 \sin (\pi / n)},
$$




$$
O B=O D+D B=\frac{d}{2 \sin (\pi / n)}+\frac{d}{2}=\left(1+\frac{1}{\sin \pi / n}\right) d
$$

In the general case for any quantities casing:

$$
D=\left(1+\frac{1}{\sin \pi / n}\right) d .
$$

The total frontal resistance is equal to:

$$
P_{\text {comeback.wedge }}=\frac{\pi+4(n-1)}{8} d^{2} E_{\text {soil }}(1+f c t g \beta) .
$$

Determine the ratio of frontal perforation resistance by cone and wedge tips with taking into account (11):

$$
\frac{P_{\text {comeback.cone. }}}{P_{\text {comeback.wedge }}}=\frac{\pi D^{2}}{[\pi+4(n-1)] d^{2}}=\frac{\pi\left(1+\frac{1}{\sin \pi / n}\right)^{2} d^{2}}{[\pi+4(n-1)] d^{2}}=\frac{\pi\left(1+\frac{1}{\sin \pi / n}\right)^{2}}{\pi+4(n-1)}
$$

Will define dependence of size of circle, what is described round a few casing fixed alongside. Will consider a few variants of reaching of pipes an amount: 2,3 , and $n$ piece.

Putting a value in a formula (8) at an identical size one casing will define the relation of resistance of pricking cone and wedge tips.

$$
\begin{aligned}
& \text { If } n=2 \text { then } \frac{P_{\text {comeback.cone. }}}{P_{\text {comeback.wedge }}}=1.76 \text {. If } n=3 \text { then } \frac{P_{\text {comeback.cone. }}}{P_{\text {comeback.wedge }}}=1.309 . \\
& \text { If } n=4 \text { then } \frac{P_{\text {comeback.cone. }}}{P_{\text {comeback.wedge }}}=1.209 . \text { If } n=5 \text { then } \frac{P_{\text {comeback.cone. }}}{P_{\text {comeback.wedge }}}=1.2 . \\
& \text { If } n=10 \text { then } \frac{P_{\text {comeback.cone. }}}{P_{\text {comeback.wedge }}}=1.44 \text {. If } n=15 \text { then } \frac{P_{\text {comeback.cone. }}}{P_{\text {comeback.wedge }}}=1.79 .
\end{aligned}
$$

\section{Methodology of calculation of total resistance of moving of wedge tip and flat directing in soil}

The lateral pressure of the soil acts on the entire perimeter of the body of the tip, which creates additional resistance from forces of friction of soil on lateral walls and edges of tip with rounding. Will define this resistance.

The average pressure of the soil on the side walls and the tips of the tip is equal $[4,6]$

$$
q_{\text {midle }}=2 c \cdot \operatorname{tg}\left(\frac{\pi}{4}+\frac{\varphi_{0}}{2}\right)+\frac{a_{q}}{2} h .
$$

where $c$ - coefficient of soil adhesion; $\varphi_{0}$ - corner of internal friction of soil; $a_{q}$ - coefficient of proportion $\left(a_{q}=0.026 \mathrm{MPa} / \mathrm{m}\right) ; h$ - depth of placing of tip (the depth of laying of communications). 
The length of the perimeter of the body of the tip is equal to

$$
L_{\text {perimeter }}=2(n-1) d+\pi d .
$$

Resistance is from forces of friction it is determined through the plaza of side of tip that the average pressure, and equals:

$$
F_{\text {friction }}=[\pi d+2(n-1) d] b_{\text {direktional }} f\left[2 c \cdot \operatorname{tg}\left(\frac{\pi}{4}+\frac{\varphi_{0}}{2}\right)+\frac{a_{q}}{2} h\right] .
$$

where $b_{\text {direktional }}$ - width of the lateral surface of the tip (fig. 1); $f$ - a coefficient of friction of soil is on material of tip.

Then total resistance of tip can differ to 2 times from the type of soil and from 1.2 to 1.76 times depending on the amount of casing, and finally has a look:

$$
\begin{aligned}
P_{\Sigma}=P_{\text {comeback.wedge. }}+F_{\text {friction }}=\frac{\pi+4(n-1)}{8} d^{2} E_{\text {soil }}(1+f c t g \beta)+ \\
+[\pi d+2(n-1) d] b_{\text {direktional }} f\left[2 c \cdot \operatorname{tg}\left(\frac{\pi}{4}+\frac{\varphi_{0}}{2}\right)+\frac{a_{q} \cdot h}{2}\right]
\end{aligned}
$$

\section{Methodology of calculation of equivalent and optimal sizes of wedge tip is with performances}

The construction of tip is offered in that wedge part is done with performances, what removes operating of resilient deformations and accordingly force of friction under the perimeter of calibrating part.

Will define the minimum thickness of wedge (Fig. 3) with performances $a_{\text {wedge }}^{\min }$, what removes operating of resilient deformations under the perimeter of tip:

$$
a_{\text {wedge }}^{\text {min }}=a+\Delta a \text {. }
$$

what removes operating of resilient deformations under the perimeter of tip Hooke [1].

$$
\sigma_{1}=E_{V} \varepsilon
$$

where $E_{V}$ - modulus of resiliency under volume compressed soil (module of by volume deformation $) ; \varepsilon$ - relative deformation of the soil $(\varepsilon=\Delta a / a)$.
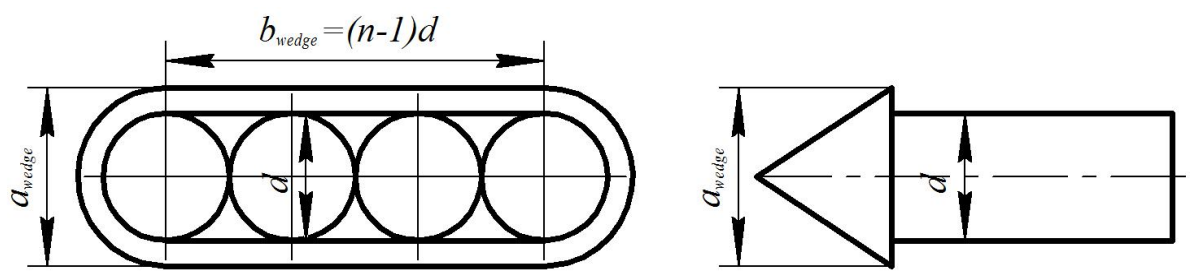

Fig. 3. Scheme of the working elements in the form of a wedge with protrusions. 
Then in accordance with [1, p. 247].

$$
\Delta a=\frac{\sigma_{1}}{E_{V}} a .
$$

For solid sandy loam $\Delta a=\frac{0.108}{0.95} a=0.114 a\left(a_{\text {min }}=1.114 a\right)$.

For noncompressed clay loam $\Delta a=\frac{0.157}{0.64} a=0.245 a\left(a_{\min }=1,24 a\right)$.

For plastic clay $\Delta a=\frac{0.167}{0.477} a=0.35 a\left(a_{\min }=1.35 a\right)$.

Thus

$$
a_{\text {wedge }}^{\min }=a+\frac{\sigma_{1}}{E_{V}} a=\left(1+\frac{\sigma_{1}}{E_{V}}\right) a .
$$

A decline of resistance of wedge tip is with performances at a minimum thickness $a_{\text {wedge }}^{\min }$ it is resulted on (Fig. 4).

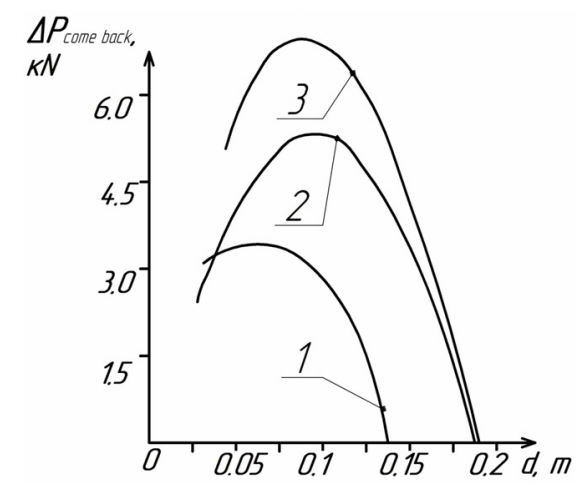

Fig. 4. Dependence of reduction of resistance to perforation wedge-shaped tip with performances from the diameter of the communications $(\mathrm{n}=2): 1$ - plastic clay; 2 - noncompressed clay loam; 3 solid sandy loam.

From (Fig. 4) it is evident that the maximum reduction in resistance pricking of wedge tip with performances depends on the type of soil, and diameter linear-extending object LEO, what are simultaneously laid.

For determination of maximal size casing will consider a difference between total resistance of wedge tip without performances (17) and the ground resistance of the tip with the projection, what takes into account resistance of frontal surface of wedge tip only, but eliminates the action of resilient deformation of soil, but accordingly force of friction for the surfaces of him calibrating part. For implementation of condition of absence of forces of friction on the surface of calibrating part and determination of force of resistance of soil tip with protrusion at calculation dependence instead of dependence of diameter LEO insert the minimum wedge size (21) and get the following expression: 


$$
\begin{aligned}
& \Delta P_{\text {comeback.wedge }}=P_{\Sigma}-P_{\text {comeback.wedge }}^{\triangleright}=\frac{\pi+4(n-1)}{8} E_{\text {soil }}(1+f c t g \beta) d^{2}+ \\
& +[\pi+2(n-1)] f b_{\text {direktional }}\left[2 c \cdot \operatorname{tg}\left(\frac{\pi}{4}+\frac{\varphi_{0}}{2}\right)+\frac{a_{q}}{2} h\right] d- \\
& -\frac{\pi+4(n-1)}{8} E_{\text {soil }}(1+f \operatorname{ctg} \beta)\left(1+\frac{\sigma_{1}}{E_{V}}\right)^{2} d^{2}= \\
& =\frac{\pi+4(n-1)}{8} E_{\text {soil }}(1+f c t g \beta)\left[1-\left(1+\frac{\sigma_{1}}{E_{V}}\right)^{2}\right] d^{2}+ \\
& +[\pi+2(n-1)] f b_{\text {direktional }}\left[2 c \cdot \operatorname{tg}\left(\frac{\pi}{4}+\frac{\varphi_{0}}{2}\right)+\frac{a_{q}}{2} h\right] d
\end{aligned}
$$

Differentiating the got expression (24) relatively $d$ will get:

$$
\begin{aligned}
& \frac{\partial \Delta P_{\text {come back.wedge }}}{\partial d}=2 \frac{\pi+4(n-1)}{8} E_{\text {soil }}(1+f c t g \beta)\left[1-\left(1+\frac{\sigma_{1}}{E_{V}}\right)^{2}\right] d+ \\
& +[\pi+2(n-1)] f b_{\text {direktional }}\left[2 c \cdot \operatorname{tg}\left(\frac{\pi}{4}+\frac{\varphi_{0}}{2}\right)+\frac{a_{q}}{2} h\right]=0
\end{aligned}
$$

Deciding the got equalization (23) relatively $d$ will get calculation of optimal size of diameters of pipes for their gasket by a wedge working elements:

$$
d_{\text {onm }}=\frac{4 f b_{\text {direktional }}(\pi+2(n-1))\left(2 c \cdot \operatorname{tg}\left(\frac{\pi}{4}+\frac{\varphi_{0}}{2}\right)+\frac{a_{q}}{2} h\right)}{(\pi+4(n-1))\left(\left(1+\frac{\sigma_{1}}{E_{V}}\right)^{2}-1\right) E_{\text {soil }}(1+f \operatorname{ctg} \beta)} .
$$

Thus, for example for $(n=1)$ most effectively to lay communication by a wedge tip with performances in plastic clay diameter $d_{\text {optimal }}=0.096 \mathrm{~m}$; in noncompressed clay loam $d_{\text {optimal }}=0.127 \mathrm{~m}$; in solid sandy loam $-d_{\text {optimal }}=0.129 \mathrm{~m}$. this diameter depends on the type of soil, geometrical parameters of tip, depths of gasket and from an amount LEO, what are simultaneously laid.

Determine the diameter of the communications, at that a tip with performances is not effective, id est $\Delta P_{\text {comeback.wedge }}=0$. From equalization (22) will get:

$$
\begin{gathered}
d_{\max } \geq \frac{8 f b_{\text {direktional }}(\pi+2(n-1))\left[2 c \cdot \operatorname{tg}\left(\frac{\pi}{4}+\frac{\varphi_{0}}{2}\right)+\frac{a_{q}}{2} h\right]}{(\pi+4(n-1))\left[\left(1+\frac{\sigma_{1}}{E_{V}}\right)^{2}-1\right] E_{\text {soil }}(1+f \operatorname{ctg} \beta)} \\
d_{\text {optimal }}=\frac{d_{\max }}{2} .
\end{gathered}
$$


Calculations are defined (for example for $n=1$ ), that the maximum diameter of the effective use of the wedge tip with the protuberance is in solid sandy loam $d_{\max } \geq 0.258 \mathrm{~m}$, in noncompressed clay loam $d_{\max } \geq 0.254 \mathrm{~m}$ and in plastic clay $d_{\max } \geq 0.192 \mathrm{~m}$.

\section{Conclusions}

Installed, that for an effective without a trench gasket simultaneously two or more underground linear-extending object communications by the method of static puncture of soil, it follows to remove the action of him resilient deformations on the perimeter of calibrating part of tip wedge working element due to the performance of basis of wedge outside the calibrated part.

Got dependence for determination of minimum thickness of wedge allowed to set optimal diameters LEO what are laid by a wedge working element. Installed(for example for $n=1$ ), that most effectively to lay communications a wedge tip with performances in plastic clay diameter $d_{\text {optimal }}=0.096 \mathrm{~m}$; in noncompressed clay loam $-d_{\text {optimal }}=0.127 \mathrm{~m}$; in solid sandy loam $-d_{\text {optimal }}=0.129 \mathrm{~m}$.

It is also educed that this diameter depends on the type of soil geometrical parameters of tip, depths of gasket and from quantity LEO, what are simultaneously laid.

Calculations were made to determine the maximum diameter effective use of a wedge tip with a projection, which makes up (for example for $n=1$ ) in solid sandy loam $d_{\max } \geq 0.258$ $\mathrm{m}$, in noncompressed clay loam $d_{\max } \geq 0.254 \mathrm{~m}$ and in plastic clay $d_{\max } \geq 0.192 \mathrm{~m}$.

\section{References}

1. V. Kovanko, O. Lukianchuk. Scientific bases of creation of earth-moving-tier machines and underground movable devices (NUWEE, Rivne, Ukraine, 2015)

2. K. Glavatsky, A. Gudenko. Herald of the DSEA, 3, 101-105, (2015)

3. S. Balezny. Bulletin KNAHU, 76, 138-141, (2017)

4. S. Kravets, O. Posmituha, V. Suponyev. Construction, materials science, mechanical engineering, PSACEA, 103, 91-98, (2017)

5. S. Khachaturian, V. Suponyev, V. Oleksin. Bulletin KNAHU, 73, 196-202, (2016)

6. S. Kravets, O. Posmituha, V. Suponyev, Science and transport progress. Bulletin DNURT named after Academician V. Lazaryan, 70, 89-98, (2017)

7. Zhao Jun Ling Bian. Trenchless technology underground pipes (Machinery Industry Press., China, 2014)

8. P. Goldstein, Mechanical properties of soils: stress-strain characteristics of soils. (Stroyizdat, Moscow, 1979)

9. V. Ziemskov, A. Sudakov. Sciences of Earth. Tidings of the TSU. 6, 35-38, (2005)

10. A. Pridmore, J. Geisbush. Planning and Design Pipelines (Phoenix, Arizona, 2017) 